\title{
O público produzindo sentidos na atualidade: memória e (des) estabilização
}

\author{
Tatiana Magalhães Florêncio \\ Maria do Socorro Aguiar de Oliveira Cavalcante
}

\begin{abstract}
This paper aims to analyse the meaning of public in the educational discourse over the period of Luís Inácio Lula da Silva. For this purpose, the category of meaning is taken from the theories developed in Discourse Analysis, namely the one represented by Michael Pêcheux. In this perspective, meaning is the result of an inseparable relationship between subject, language and history and is always permeated by ideology. In this study, ideology is understood within the scope of the ontological perspective focused by Lukàcs as well as Bakhtin / Volochínov's theories on the formation of language. Therefore, the objective is to reveal the effects of sense produced by the word public, considering that the slidings inherent to the discursive process are linked to their conditions of production. Indeed the starting points for the analyses are the changes occurred in the Brazilian educational process, related to State reforms. Amid these changes, the conflict among political groups in debates concerning public and private matters becomes evident in various areas, including in the educational sphere. Upon assuming the presidency, in quest for consensus on the changes he thought necessary for Brazilian education, Luiz Inácio Lula da Silva builds a seductive discourse, based on implicit and silencing, thus veiling its commitment to specific social segments.
\end{abstract}

Keywords: Speech, sense, public / private

Resumo: Este trabalho propõe-se a analisar os sentidos de público presentes no discurso educacional do governo de Luís Inácio da Silva. Para isso, toma-se a categoria de sentido, a partir das teorizações desenvolvidas na Análise do Discurso, na vertente representada por Michel Pêcheux. Nessa perspectiva, o sentido é resultado de uma relação indissociável entre sujeito, língua e história, sempre atravessada pela ideologia. Esta, por sua vez, é entendida nesse trabalho, a partir do prisma ontológico enfocado por Lukács, e das considerações de Bakhtin/Volochinov sobre a constituição da língua. Objetiva-se, pois, desvelar os efeitos de sentido de público, considerando que os deslizamentos inerentes ao processo discursivo estão vinculados as 
suas Condições de Produção. Parte-se, assim, das modificações ocorridas no processo educacional brasileiro, relacionadas às reformas do Estado. Em meio a essas mudanças, evidencia-se o conflito entre grupos políticos, nos embates acerca da discussão público/privado em diversos âmbitos, inclusive no da educação. Ao assumir a presidência, Luís Inácio Lula da Silva, na busca de consenso em relação às mudanças que considera necessárias para a educação brasileira, por meio de implícitos e silenciamentos, constrói um discurso sedutor, que oculta seu comprometimento com quaisquer segmentos sociais.

Palavras-chave: Discurso, sentido, público/privado

A palavra-chave sempre se esconde atrás da porta.

Lêdo Ivo

No contexto da Análise do Discurso, é impossível dissociar sentido e memória, pois cada dizer traz em si uma história que o constitui. Essa constituição não se encontra explícita na intenção do sujeito que enuncia, nem aparece de forma nítida àqueles que tomam conhecimento do dito, seja ou não a eles direcionado. Impossível, então, perceber essas diferenças apenas no interior do sistema linguístico. Daí recorrermos, para desenvolver as noções de público presentes nas políticas da educação brasileira, às categorias da AD que nos orientam nessa busca: as condições de produção, ideologia, memória e interdiscurso.

Para desvelar os sentidos de público, que são trazidos pelo discurso educacional do governo Lula, buscamos mostrar as Condições de Produção que permitem a emergência dessas ideias no Brasil, bem como elucidar o funcionamento da ideologia nesse entendimento. Tais concepções apresentam-se concretamente como construções (ou tentativa) de sentido hegemônicas no contexto social em que se apresentam. Assim, a materialidade da ideologia se manifesta na língua em funcionamento, por meio dos discursos que retomam e ressignificam tais dizeres. Nesse sentido, ao trazer, neste artigo, sequências discursivas selecionadas como representativas do objeto que investigamos, buscamos explicar o funcionamento da memória no processo de constituição dos sentidos.

Podemos afirmar que a memória, como categoria pertencente ao arcabouço teórico da $\mathrm{AD}$, constitui os dizeres e trabalha através do conflito da estabilização/desestabilização dos discursos. Não estamos falando aqui de uma memória social constituída como inconsciente coletivo; mas sim daquela memória que funciona discursivamente, que traz à tona o já-dito e o atualiza. Essa atualização é, muitas vezes, motivada, mas pode aparecer e permanecer sem que haja uma elaboração consciente. Por isso mesmo, elegê-la como categoria de análise de um dado discurso é partir do pressuposto de que a língua não basta por si só, e a construção do sentido ultrapassa os limites das formulações textuais. Segundo ACHARD, (2007, p.15-16),

'Se situamos a memória do lado não da repetição, mas da regularização, então
ela se situaria em uma oscilação entre o histórico e o lingüístico, na sua suspen-
são em vista de um jogo de força de fechamento que o ator social ou o analista vem
exercer sobre discursos em circulação. Este eventual jogo de força é suportado
pela relação de formas, mas estas são apenas o suporte dele, nunca estão isola-
das. Elas estão eventualmente envolvidas em relações de imagens e inseridas em
práticas'. (Grifos nossos). Ao abordar a questão da memória como constituinte fundamental dos sentidos, 
Achard nos põe a indagação sobre o que é o repetível e o como se constitui essa retomada. Certamente, um dizer pode ser repetido, enquanto concebido como organização sintática, na qual se utilizam os mesmos vocábulos. No entanto, essa repetição é inconcebível quando pensamos no processo de produção de sentidos, sobre o qual atuam determinantes que vão muito além de uma estruturação linguística. Aí implica necessariamente a análise das condições de produção.

Para a AD, o discurso vai além do texto, não somente porque se manifesta em diversos suportes - oralidade, escrita, gestualidade, imagem, mas porque se entende o texto como uma unidade mínima, uma porta de entrada para chegarmos ao discurso. De acordo com Orlandi (1996, p. 52), para a AD francesa "o texto é uma 'peça' de linguagem, que representa uma unidade significativa [...] é um objeto histórico. Histórico aí não tem o sentido de ser o texto um documento, mas discurso. Assim, melhor seria dizer: o texto é um objeto linguístico-histórico."

Ao trazermos essa reflexão para o nosso objeto de estudo, é preciso que coloquemos os dizeres elaborados pelo governo Lula, no âmbito da educação pública, em uma perspectiva histórico-concreta, ou seja, buscando mostrar os processos políticos e sociais que objetivamente direcionam este dizer. Afinal, quais memórias de educação pública são trazidas à tona quando as enunciações referem-se a essa temática?

Com relação aos sentidos de público que emergem/constituem o referido discurso, é possível perceber a memória atuando como retorno e resposta a um contexto ao qual aparentemente se contrapõe. Pensamos aqui na história recente das disputas presidenciais no Brasil, evidenciadas pela polarização PSDB-PT. A implementação da agenda de reformas neoliberais no Brasil, nos governos de FHC, foi denunciada constantemente pela oposição (tendo o PT como partido referência nesse processo) como processo privatizante, priorização do privado em detrimento do público. Quando Lula assume a presidência e pretende mostrar que ocupa uma posição política oposta à anterior, precisa se diferenciar de seu antecessor. Esse "diálogo" pode ser percebido em algumas sequências discursivas como a que segue, retirada da Carta de apresentação do $\mathrm{PDE}^{1}$ - Razões, princípios e programas.

SD 1: Em vez de simplesmente enaltecer os feitos de sua equipe, ele procura tornar transparente e acessível a lógica pública que inspira o trabalho do nosso governo, buscando uma interlocução com todos os que têm compromisso com a educação, independentemente de simpatias políticas e ideológicas. (grifo nosso).

Percebe-se nessa SD, através da utilização da restritiva "que inspira" (inspiradora desse governo), a preocupação em demarcar o diferencial entre "a lógica pública que inspira o trabalho do governo" Lula e a lógica do governo anterior. Ou seja, essa lógica é restrita/específica "do nosso governo," que é diferente do anterior.

Nesse caso, a memória de que a lógica privada era prioridade do governo anterior atravessa o dizer, dando novo sentido ao que é público (de acesso e de interesse de todos, "independentemente de simpatias políticas e ideológicas"). Além disso, marca também um posicionamento aparentemente diferencial por meio da participação (se público é de acesso a todos, o governo abre espaço (busca uma interlocução) para todos os que "têm compromisso com a educação. independentemente de simpatias políticas e ideológicas."

Vê-se aqui que o privado aparece de forma implícita, por meio da memória discursiva, com a qual é preciso estabelecer o diálogo para perceber os deslocamentos do sentido de público. Uma memória que é acionada pela oposição política a outros projetos de educação pública postos na realidade brasileira e que retomam sentidos estabelecidos

1 Programa de desenvolvimento da educação 
pelas práticas políticas e educacionais surgidas no processo de desenvolvimento do Estado. Ao mesmo tempo, há um diálogo e uma sobredeterminação dos rumos econômicos que não são definidos apenas no espaço da soberania nacional, o que significa considerar as vozes advindas de diversos espaços no processo de composição e recomposição desses dizeres postos em circulação.

Por isso, antes de apresentarmos a análise de outras sequências discursivas selecionadas, buscamos estabelecer essa relação entre memória e história apresentando um conteúdo mais genérico dos contextos nos quais esses dizeres se inserem. A referência a tais contextos nos permite reconhecer as marcas do discurso dominante, de ideologias que se sucedem. Pretendemos, com isso, abordar as condições de produção do discurso educacional sobre o público e trazer à tona as memórias que são acionadas por estes enunciados.

Em um momento mais recente da história educacional do País, especificamente nos governos de Fernando Henrique Cardoso na década de 1990, tivemos mudanças efetivas na forma de organização dessa área, relacionadas diretamente com um processo de reconfiguração do Estado para atender a demanda de grupos que buscam avançar na exploração desse universo enquanto mercado de atuação. Como tal processo já se havia verificado na educação de nível médio, especialmente na expansão apresentada durante o período da ditadura militar, o governo brasileiro, atendendo a expectativas de grupos econômicos que buscavam esse nicho mercadológico, modifica as leis e amplia a possibilidade de abertura de instituições voltadas para a formação superior, como pudemos constatar em FLORÊNCIO (2007, p.10): ${ }^{2}$

Ao tratar das políticas públicas para a educação brasileira na década de 1990, podemos identificar claramente a presença de elementos ligados às estratégias neoliberais para a educação. No caso do ensino superior, de uma maneira sintética: a) fortalecimento do papel regulador do Estado; b) diversificação das instituições aptas a oferecer esse tipo de ensino, garantindo maior amplitude de mercado; c) o descaso com as universidades públicas, como forma de reduzir custos do Estado e fortalecer o setor privado; d) caráter mercadológico dos cursos (base prática em detrimento da teórica, definição de cursos de acordo com o "interesse imediato" dos estudantes) e e) fragmentação de cursos, passando a imagem de especialização maior; entre outras características. Essas mudanças fazem parte de um processo amplo de alterações, que têm como propósito a expansão de um exército industrial de reserva mais qualificado.

Naquele momento, verificamos nos discursos elaborados pelo governo FHC, que não havia uma estratégia discursiva de confluência de sentidos entre público e privado, mas uma oposição semântica entre as esferas. Essa forma de apresentação era acompanhada por dizeres que qualificavam ou desqualificavam os dois polos, criando efeitos de sentido que traziam à tona uma memória historicamente construída do público enquanto espaço ineficaz e atrasado, ao contrário do setor privado, concatenado com avanços diversos da economia da tecnologia. Para melhor exemplificar esse estudo, trazemos aqui um trecho de entrevista do Ministro da Educação de FHC, Paulo Renato de Sousa, ao final de sua segunda gestão, na qual comenta a ineficiência das universidades públicas: "a ineficiência decorre de uma situação histórica de haver isonomia salarial, de não se cobrar nada, de não haver nenhuma parcela do salário vinculada ao desempenho. São fatores estruturais"3.

\footnotetext{
2 Nesse trabalho, em que fazemos uma análise da expansão da educação superior privada em Alagoas, buscamos entender esse processo através da reconfiguração das políticas públicas para o ensino superior e a análise do discurso de donos e diretores de instituições abertas no Estado durante esse período.

3 O Crescimento segundo Paulo Renato. Disponível em: www.educacional.com.br/entrevistas/entrevista0076. asp. Acesso em abril de 2006.
} 
Nossa intenção, ao trazer esse dizer é perceber que o modo do discurso utilizado direciona os sentidos de uma memória sobre a educação brasileira (nesse caso, especificamente a educação superior) que relaciona fatores históricos e a não cobrança do governo por resultados. Trata-se das cobranças de empenho por parte daqueles diretamente envolvidos no setor educacional público superior - professores e funcionários, - tendo como função imediata, a nível do intradiscurso, justificar a qualificação de ineficiente atribuída às universidades públicas (a ineficiência decorre de uma situação histórica,). Como dissemos, a memória funciona discursivamente, e não depende apenas da intenção do sujeito trazer determinados sentidos à tona.

Assim, se relacionamos o dizer de Lula sobre a lógica pública que rege o trabalho de seu governo e a de Paulo Renato, em que o público é classificado como ineficiente, percebemos que em ambas o privado é silenciado. No caso de Paulo Renato, a ineficiência é associada a fatores de organização presentes historicamente na lógica privada (desempenho, cobrança, política salarial associada a desempenho e avaliação).

É justamente essa identificação do Estado com a lógica privada, presente no discurso do governo FHC, que permite um retorno da memória a esse direcionamento, fazendo com que o público tenha seu sentido associado, de forma imediata, a uma oposição da lógica privada. Para isso, não é preciso enunciar explicitamente tal oposição, já que "não há como não considerar o fato de que a memória é feita de esquecimentos, de silêncios. De sentidos não ditos, de sentidos a não dizer, de silêncios e silenciamentos." (ORLANDI, 2007, p.59). Esses vazios da memória são retomados em um processo constante de (re) interpretação do real, à luz das necessidades humanas de responder às questões que lhes são colocadas pelo movimento da história.

Assim sendo, esse processo de atribuição de sentidos à educação pública presente nos discursos do governo Lula responde politicamente ao contexto imediatamente anterior do qual quer aparentar divergir. Na aparência do fenômeno, havia uma disputa, entre dois projetos para o Brasil: o primeiro, como sendo de continuidade explícita das políticas neoliberais já aplicadas no País (representadas pela aliança PSDF-PFL nas figuras de José Serra e Geraldo Alckmin como possíveis sucessores de Fernando Henrique Cardoso); o segundo referente à aplicação de um projeto de cunho social-desenvolvimentista, o qual, de maneira genérica, estabelecia uma relação de revisionismo na aplicação de medidas para o crescimento do País e para a redução dos índices de desigualdade social.

Assim, o governo FHC trabalha discursivamente a oposição público-privado para a reconfiguração desses espaços, e o faz apoiado em uma memória socialmente constituída (mesmo que apenas idealmente ${ }^{4}$ ) acerca das concepções de público e privado instituídas pelo modelo do Estado de Bem-Estar social. O governo Lula, por sua vez, precisa responder a essa elaboração, de forma a ressignificar o público almejado por sujeitos politicamente ativos, que se colocavam como base social de apoio e ansiavam pela aplicação de medidas identificadas com um modelo de Estado que provesse o público. Concretamente, ele não poderia utilizar a mesma estratégia de oposição e diferenciação entre as esferas, sob o risco de não se diferenciar do seu antecessor na construção imagética desses espaços.

Ora, soma-se a isso o fato de que a reelaboração da imagem de Lula, para alcançar a aceitação da maior parte da população brasileira e, com isso, possibilitar que este alçasse o posto de presidente, baseia-se em uma perda parcial da identidade que o constituiu como ícone do movimento operário brasileiro. Essa memória é trazida à tona enquanto

4 Estamos aqui nos referindo ao fato de que, na história da educação brasileira, e mesmo por conta da própria organização e do papel desenvolvido pelo Estado, sempre existiram incentivos ao sistema educacional privado, especialmente por meio das bolsas de estudos. 
compromisso histórico com os mais pobres e, portanto, dialoga com a noção de público, na perspectiva de provimento do Estado. Essa perspectiva impõe não uma mudança radical na aplicação de medidas educacionais por parte do governo, mas um rearranjo o qual implica uma resposta aos interesses postos pelo mercado, após a crise do Estado de Bem-Estar Social.

O dilema posto mundialmente através de documentos elaborados por organismos multilaterais visando à adequação dos países aos diversos modelos propostos para a educação - em especial à educação superior -, ganha contornos e conflitos distintos, de acordo com a tradição histórica do papel atribuído à educação em cada um desses Estados, bem como à concepção defendida pelos grupos sociais atuantes nesse contexto. É aí que a memória atua, como um retorno à tradição histórica, ao mesmo tempo em que os processos discursivos adaptam-se ou diferenciam-se nesse espaço-tempo, em um diálogo constante com elaborações outras.

Pechêux nos alerta que, ao tratar da memória enquanto constituinte dos processos discursivos, estamos trabalhando numa linha tênue entre "o acontecimento que escapa à inscrição, que não chega a se inscrever" e "o acontecimento que é absorvido na memória, como se não tivesse ocorrido" (2007, p. 50). Dessa maneira, retomar um dizer é atualizá-lo. É promover, no espaço do atual, uma possibilidade de constituir o sentido a partir da dualidade manutenção x mudança - não que, em seu cerne, toda mudança enseje transformação em seu sentido radical, qual seja, uma mudança estrutural profunda. Essa atualização se sustenta na memória que constitui os dizeres, que dá sentido às palavras existentes e que possibilita os múltiplos significados. Ela pode ser retomada pelo sujeito que enuncia de forma consciente, mas seu funcionamento não é limitado ao previsível, pois, como já dissemos, a língua é atravessada por falhas e deslocamentos que a constituem.

Assim, podemos dizer que a intencionalidade não absorve as possibilidades de deslocamentos, pois "qualquer decisão que suscita uma ação tem lugar em circunstâncias que o homem, que realiza a posição teleológica, não está nunca em condições de prever completamente e, portanto, de controlar." (LUKÁCS, s.d, p. IX). Portanto, esses deslocamentos podem ser acionados pelo próprio discurso aparentemente estabilizado ou mesmo pelas impressões singulares de um sujeito, por meio de um discurso interior o qual remete à questão do indivíduo singular ${ }^{5}$. Esse processo de constante movimento dos sentidos é atualizado pela memória. Como esclarecem Florêncio et alli, (2009, p.79), a memória discursiva é "um lugar de retorno a outros discursos, não como repetição mas como ressignificação".

Perceber o processo de ressignificação dos sentidos de público no discurso de Lula sobre a educação exige, assim, que relacionemos os dizeres, considerados como fragmentos representativos de um discurso (que é entendido como práxis), à concretude das manifestações linguísticas, ao processo sócio-histórico que o engendra e sobre o qual ele atua. Portanto, ao falarmos de um discurso educacional, ao tomar como objeto o discurso SOBRE a educação no governo de Luís Inácio Lula da Silva, estamos partindo do pressuposto de que esse discurso responde a questões mais amplas, presentes na realidade social - contexto imediato - e é determinado por questões outras que não relativas apenas à esfera educacional - contexto amplo -. Em termos objetivos, pensamos aqui na relação estabelecida, e que está presente nas elaborações do governo Lula nessa área específica, entre educação e desenvolvimento. Dessa maneira, tentar identificar os deslocamentos do

5 O discurso interior é apresentado por Bakhtin/Volochinov como sendo fundamental no processo de formação do sujeito, da estruturação da sua consciência. 
público nesse discurso nos coloca a tarefa de não nos atermos à sua enunciação concreta (entendida como transparente), mas buscar, nos implícitos e silenciamentos determinados social e historicamente, as relações que estabelece.

É preciso destacar que o silêncio é colocado aqui como uma categoria de análise. Estamos falando de um silêncio que atravessa os dizeres, que constitui a linguagem (dizer determinadas palavras significa, necessariamente, deixar de dizer, colocar em silêncio outras) o que possibilita os deslocamentos para além dos espaços determinados. Pensar a totalidade nos estudos do discurso significa ultrapassar as fronteiras do linguístico e perceber como o real da história determina os processos discursivos. De acordo com Magalhães $(2005$, p. 13) "a análise da realidade, sob a perspectiva marxista, busca desvelar a totalidade do objeto estudado, entendendo-se que a totalidade é constituída pela relação entre os aspectos fenomênicos e a essência do recorte do real".

Isso implica considerar esse objeto como processo sócio-histórico que produz sentidos e que, se por um lado é produto das determinações, por outro se volta à realidade para nela intervir, como orientação das ações dos sujeitos, inseridos nesse contexto. Esse entendimento do discurso enquanto práxis, caracterizado enquanto teleologia secundária ${ }^{6}$ e que, portanto, está vinculada ao todo social, implica também trazer para os estudos do discurso as categorias da singularidade e da particularidade, ou seja, trabalhando a realidade como um complexo de complexos. Como nos lembra Magalhães (2005, p. 24) "a singularidade discursiva pressupõe necessariamente o outro, já que é constitutivamente dialógica". Sendo assim, o singular está relacionado ao contexto social imediato e às relações que são estabelecidas/consolidadas/impulsionadas por meio desses dizeres.

Esse singular relaciona-se com a totalidade através de diversas mediações, o que faz com que esse processo não seja uma dedução mecânica: os fatos, inclusive os linguístico-discursivos, não derivam diretamente das determinações socioeconômicas No entanto, sendo o real sempre mais complexo que qualquer reflexão que se faça sobre ele, é preciso que abordemos nosso objeto a partir de um determinado prisma, sem perder de vista o “todo articulado". O real do discurso é assim, a função ideológica que assume na história. Ainda assim, não podemos partir da conjuntura socioeconômica para explicar o que está colocado discursivamente, pois isso implicaria uma análise de conteúdo (os discursos como exemplificadores de uma posição identificada fora dele). Os dizeres são o ponto de entrada no discurso que, como vimos, passa pela combinação linguística, mas se põe para além dela.

Como diz Orlandi (2005, p. 39): "todo discurso é visto como um estado de um processo discursivo mais amplo, contínuo. Não há, desse modo, começo absoluto nem ponto final para o discurso". Esse "processo discursivo mais amplo" leva-nos a reafirmar que os caminhos pensados/articulados para a educação não estão isolados de questões políticas e econômicas as quais dizem respeito a mudanças globais no modo de pensar e agir, próprios da nossa forma de sociabilidade, daí a necessidade de falarmos das CP que permitem o aparecimento dos discursos do Plano de Desenvolvimento da Educação (PDE).

É no segundo mandato que o presidente Lula investe mais fortemente na tentativa de hegemonizar a concepção de educação que norteia suas políticas. No primeiro semestre

6 Valemo-nos do conceito de teleologia secundária que está presente na obra de Lukács e está diretamente relacionado à concepção ontológica do ser social. Sendo o homem um ser que dá respostas de acordo com as necessidades e possibilidades postas no real, ele se vale de um momento ideal, a prévia-ideação, que acompanha/ antecede a ação, a escolha em si. Essa questão está posta nas relações homem-natureza (teleologia primária) e nas relações homem-homem (teleologia secundária). Grosso modo, a teleologia secundária representa a ação dos homens sobre outras consciências. 


\section{Conexão Letras}

de 2007, é lançado este documento, cujas propostas não se restringem ao seu mandato: apresentam-se metas e ações que devem ser realizadas nos próximos 15 anos. Envolve, assim, todas as esferas governamentais responsáveis pela oferta, controle e regulação educacional e versa sobre as diversas modalidades e níveis de ensino. Essa perspectiva, como se verifica pelo próprio funcionamento da memória discursiva nos dizeres de Lula, ainda está presente na sociedade de forma hegemônica, como herança de um modelo de sociedade advinda do Estado de Bem-Estar Social, qual seja: o público como o que é de acesso a todos e provido pelo Estado e o privado como o oposto: o que é de acesso restrito, e controlado por forças de interesse particular.

Assim, ao tomarmos o universo discursivo político-governamental da atualidade, sobre a educação, temos um acontecimento histórico significativo: o lançamento do Plano de Desenvolvimento da Educação, (PDE) que representa os caminhos pensados e aplicados pelo atual governo para esta área, e que se põe como parte de um projeto ainda maior: o Plano de Aceleração do Crescimento (PAC). Interessa-nos aqui perceber as articulações discursivas em torno do PDE, que se coloca para além de um "plano de governo", Pretendemos identificar os mecanismos pelos quais o discurso governamental vai direcionando - ou buscando direcionar - sentidos. Vejamo-la, em sua completude.

\section{Carta de apresentação do livro PDE - Razões, princípios e programas.}

O que está sintetizado nestas páginas é muito mais que uma prestação de contas. Nelas, o Ministro da Educação, Fernando Haddad, expõe - em tom de diálogo com a sociedade e principalmente com os educadores - os princípios políticos, os fundamentos teóricos, os métodos educacionais e o passo-a-passo administrativo que têm marcado sua gestão à frente do Ministério.

Em vez de simplesmente enaltecer os feitos de sua equipe, ele procura tornar transparente e acessível a lógica pública que inspira o trabalho do nosso governo, buscando uma interlocução com todos os que têm compromisso com a educação, independentemente de simpatias políticas e ideológicas. Não é por acaso que os mais diferentes setores sociais, dos trabalhadores aos empresários, dos professores aos alunos, das escolas privadas às escolas públicas, em todas as regiões, têm reconhecido a consistência das políticas públicas voltadas para a educação: Prouni, Universidade Aberta, Fundeb, Piso Salarial Nacional do Magistério, IDEB, Reuni, IFET, entre outras iniciativas. Muito já foi feito e muito mais temos que fazer.

A ideia do livro, portanto, não é a de proclamar conquistas. O sentido é outro: convidar todos os educadores, das mais variadas visões, os professores, os alunos, a sociedade brasileira, em suma, para conhecer mais de perto os fundamentos do trabalho que vem sendo desenvolvido, visando ao seu aprimoramento cada vez maior.

A educação, como sempre afirmamos, é um caminho sólido para o Brasil crescer beneficiando todo o nosso povo. O Plano de Desenvolvimento da Educação (PDE) é um passo grandioso nesse sentido.

Aos que querem entender os fundamentos desse trabalho, boa parte das respostas está aqui.

Luiz Inácio Lula da Silva - Presidente da República

Podemos perceber uma característica relevante do funcionamento discursivo sobre o público na educação, materializada em sequências selecionadas a partir de uma regularidade no processo de negação/antecipação. Esse entendimento pode ser encontrado já na primeira frase apresentada no texto:

S.D 1 - O que está sintetizado nestas páginas é muito mais que uma prestação de contas. 
Segundo Orlandi (2005, p. 39), o mecanismo da antecipação diz respeito ao fato de que "todo sujeito tem a capacidade de experimentar, ou melhor, de colocar-se no lugar em que seu interlocutor 'ouve' as suas palavras". É essa antecipação, de acordo com a autora, que "regula a argumentação". Ao dizer que o livro é "muito mais que uma prestação de contas", significa, ao mesmo tempo, dizer que ele "é (também), uma prestação de contas, mas não é essa a sua principal finalidade" ou, que "não é apenas uma prestação de contas". "Prestação de contas" é aqui utilizado no contexto de "apresentação do que foi feito pelo governo", e não apenas como "apresentar aos interessados os gastos".

Ao iniciar o texto com esse enunciado, Lula antecipa-se aos interlocutores que se colocam como opositores às políticas educacionais em curso, além de minimizar o efeito propagandístico de tal empreendimento. Assim, dialoga diretamente não com o público a quem supostamente o livro se destina - os educadores e gestores que o colocarão em prática e tentarão atingir essas metas - mas com aqueles que supõem o empreendimento como sendo uma estratégia política de continuidade de um programa formulado por um grupo específico e que já estava no controle do Estado há duas gestões?

Sabe-se que a resposta acerca das práticas políticas na área educacional obtém-se, cada vez mais, através de indicadores que transformam em números o desempenho, o acesso, a aprovação e a expansão de alunos e instituições, os quais são, realmente, expostos ao longo do livro. É justamente esse o ponto (a melhoria de indicadores) que o PDE pretende, explicitamente, alcançar. A continuidade do que foi conquistado não pode ser garantida, de modo que isso é feito apenas como expectativa, enquanto prospecção baseada em dados, diagnósticos e projeções concretas (alcançar nota 6 no IDEB ${ }^{8}$ até 2021, por exemplo, ou alcançar o patamar de $6 \%$ a $7 \%$ de investimentos do Produto Interno Bruto brasileiro na educação ${ }^{9}$, contra os $4 \%$ atuais). O que percebemos aqui é que o então presidente nega o livro como mero objeto de contemplação, de propaganda: "O sentido é outro." O "verdadeiro" sentido nos é apresentado na próxima sequência.

SD 2 O sentido é outro: convidar todos os educadores, das mais variadas visões, os professores, os alunos, a sociedade brasileira, em suma, para conhecer mais de perto os fundamentos do trabalho que vem sendo desenvolvido, visando ao seu aprimoramento cada vez maior.

Por aí, pode-se inferir que a "real" intenção do governo, é envolver, aproximar, "todos os educadores, das mais variadas visões, os professores, a sociedade brasileira, em suma, para conhecer mais de perto os fundamentos do trabalho que vem sendo desenvolvido". Está implícito, pois, que os sujeitos do processo educacional "todos os educadores, das mais variadas visões, os professores, os alunos", estiveram ausentes da elaboração desse documento; apenas agora são "convidados a conhecê-lo de perto.

Outro aspecto interessante é a escolha pela apresentação do conteúdo do trabalho como algo dado em SD1 (O que está sintetizado nestas páginas), e não a colocação imediata do presidente como sujeito da ação, como se pressupõe nos discursos políticos (um possível "sintetizamos nessas páginas"). A impessoalidade também aparece em SD 2,

7 Referimo-nos aqui à continuidade do PT no governo brasileiro e a projeção de um novo nome para assumir o lugar deixado por Lula à época do lançamento do PDE, o que consolidou-se, como sabemos, com a eleição de Dilma Roussef.

8 Índice de Desenvolvimento da Educação Básica

9 Interessante notar o silenciamento presente nessa meta anunciada no PDE em relação ao Plano Nacional de Educação então em vigência quanto à aplicação de $10 \%$ do PIB nessa área. Como se sabe, essa meta não está presente no PNE devido ao veto do ex-presidente FHC à recomendação, feit por parte dos segmentos que discutiram e elaboraram o Plano. 
quando se opta por chamar os interlocutores a "conhecer mais de perto os fundamentos do trabalho que vem sendo desenvolvido" e não "que desenvolvemos" (já que ele - Lula - é o responsável primeiro pelas ações do governo estatal).

Essa escolha coloca o então presidente na posição de "observador", conforme dissemos pouco antes, ou seja, como membro não diretamente responsável por essa construção. Essa apresentação mostra-se favorável ao enunciante na medida em que o documento não foi redigido por ele, mas por técnicos e pessoas que pensam e agem "em prol da educação". Ao mesmo tempo, a elaboração ganha seu aval, aparentando colocar-se para além de interesses imediatos do governo. Começar o texto dessa forma permite ao então presidente afastar-se, mesmo que apenas inicialmente, de uma imposição governamental, como uma afirmação enfática. Tal estratégia é percebida ainda em outros pontos desse mesmo texto.

S.D 3 - Em vez de simplesmente enaltecer os feitos de sua equipe, ele [o Ministro da Educação, Fernando Haddad] procura tornar transparente e acessível a lógica pública que inspira o trabalho do nosso governo.

Trata-se aqui do segundo parágrafo da carta de apresentação, o qual se inicia com "em vez de", funcionando como indicativo de exclusão, mas que, discursivamente, traz de forma explícita uma informação que, na verdade, não se contrapõe à oração subsequente, pois ele simplesmente não enaltece os feitos de sua equipe (ou seja, faz isso, mas não só isso). Na verdade, ele enaltece, mas não se atém a isso, porque "procura tornar transparente e acessivel a lógica pública que inspira o trabalho do nosso governo". O modalizador simplesmente, portanto, coloca o verbo enaltecer em uma posição inferior em relação a outros possíveis verbos de cunho semântico aparentemente neutro, tais como: apresentar, mostrar, exibir.

A referência direta ao nome do Ministro que respondia pela Educação no País à época (e que ainda se manteve no cargo durante o atual governo de Dilma Houssef até sua candidatura à prefeitura de São Paulo) atende a uma identificação do sujeito (governo Lula) e incorpora-se à mesma estratégia discursiva de negação. Assim, afirma-se por outros caminhos, especialmente por meio dos implícitos, já que uma negação dialoga necessariamente com uma afirmação que a antecede e que se inscreve no já-dito. É importante salientar que, embora não haja em SD3 nenhuma palavra negativa a qual indique explicitamente essa intenção, a utilização de "em vez de" assume essa função ao aparentemente contrapor uma afirmação à outra, pois a leitura mais imediata do dizer a coloca como elemento que exclui a informação subsequente em detrimento de outra.

É ainda por meio desse operador argumentativo ("em vez de") que podemos perceber o funcionamento dos implícitos em SD2: Fernando Haddad, pela prática de não enaltecimento dos feitos de sua equipe, identifica-se com a mesma lógica do governo do qual faz parte, a lógica pública. E essa lógica, na perspectiva intradiscursiva, opõe individualidade e coletividade, e, ao mesmo tempo em que nega essa autoafirmação do Ministro, coloca-o como responsável direto, mesmo que como comandante de um projeto. Esse entendimento é corroborado pela utilização de sua, qualificando equipe, o que, ao mesmo tempo em que alude ao trabalho de não apenas um, remete à lógica empresarial do comando, do responsável, de uma pessoa que deve estar à frente para fazer valer um trabalho.

Isso significa que é principalmente a ele (Haddad) que é atribuído o resultado (o livro) das ações do governo na área da educação, especialmente a elaboração do PDE. Não nos interessa aqui elucidar as questões acerca de pretensões políticas do Ministro, mas antes pensar esse funcionamento discursivo do nós, não como negação do indivíduo, mas como incorporação dos sujeitos no processo guiado pela "lógica pública". Afinal, que efeitos esses deslocamentos provocam? 
A passagem do discurso que começa buscando a impessoalidade, mas assume, em alguns trechos da carta, a primeira pessoa do plural, garantindo a entrada explícita do sujeito enunciador (a lógica pública que inspira o trabalho do nosso governo; Muito já foi feito e muito mais temos que fazer; A educação, como sempre afirmamos, é um caminho sólido para o Brasil crescer beneficiando todo o nosso povo).

Assim, esse sujeito, que teria como função apenas "apresentar" o livro, passa a ser percebido como corresponsável (o que já está implícito no fato de ser uma publicação do governo). Percebe-se que há a tentativa de reconhecimento de um trabalho elaborado da equipe, mas sem o total afastamento, uma vez que há a inserção (discreta) do chefe do Estado brasileiro por meio da utilização de verbos ou pronomes na primeira pessoa do plural.

Se a lógica do público está presente em todo o governo federal sob o comando de Lula, conforme vimos em SD3, então é preciso perceber as relações para além do discurso sobre a educação, que é, antes, uma parte não dissociada de elaborações mais gerais sobre a política estatal desse governo.

Para avançarmos nesse entendimento, trazemos a sequência discursiva que inicia o terceiro parágrafo do mesmo texto de apresentação do livro do qual retiramos as sequências apresentadas anteriormente. Mais uma vez, percebemos a negação como estratégia de funcionamento discursivo que remete à construção e estabelecimento/ deslocamento do signo público.

S.D 4 - Não é por acaso que os mais diferentes setores sociais, dos trabalhadores aos empresários, dos professores aos alunos, das escolas privadas às escolas públicas, em todas as regiões, têm reconhecido a consistência das políticas públicas voltadas para a educação.

"Não é por acaso" funciona aqui, novamente, como afirmativa de um propósito, podendo ser parafraseada por "é com toda razão" ou "é por meio de ações concretas". Refere-se explicitamente ao reconhecimento do que vem sendo construído/elaborado até então pelo governo em relação à área educacional, dado como fato concreto, uma vez que ao afirma que um grande número de sujeitos individuais e coletivos (os mais diferentes setores sociais, dos trabalhadores aos empresários, dos professores aos alunos, das escolas privadas às escolas públicas, em todas as regiões) "têm reconhecido" a consistência das políticas públicas voltadas para a educação, coloca-se tal reconhecimento como consenso.

Daí é possível apreender uma generalidade que apresenta as diferenças como realidade (há setores sociais que possuem interesses diversos), mas cuja unidade é conquistada pelas políticas públicas desse governo. A unidade possibilitaria entender a diversidade não como divergência. Logo, a "lógica pública" imprimida por este a diversos setores, em especial à educação, é colocada aqui como aceita e exaltada pela população que depende da educação, beneficiários das ações governamentais, seja na esfera privada (empresários e escolas privadas), seja pela esfera pública (trabalhadores e escolas públicas). Dessa maneira, a lógica pública é entendida para além da lógica do Estado, aquele que age a fim de garantir o "bem-estar" geral da população, independentemente da posição que os sujeitos individuais ou coletivos ocupem na sociedade. Em contraposição, sendo o Estado o responsável por direcionar as ações, seu caráter de ação é colocado para além dos interesses particulares de grupos ou pessoas.

Montaño identifica esse movimento como uma reconfiguração das relações público-privado a partir da reorganização do Estado capitalista no momento pós-crise de 1973 e em resposta às ofensivas neoliberais. De acordo com o autor, "a ordem burguesa efetivamente, desde sua constituição como hegemônica, desenvolve-se contendo e reproduzindo 
contradições estruturais e fundantes entre o público e o privado." ${ }^{10}$ (2008, p.27). A maneira como essa relação é apresentada responde hoje, portanto, à necessidade de restabelecer o papel do Estado. Isso, em um momento histórico em que o modelo de Estado de Bem-Estar não era mais interessante - na verdade, não poderia mais ser sustentado - e o modelo neoliberal vinha sofrendo com a oposição da sociedade para a manutenção dos direitos conquistados historicamente.

No caso do Brasil, especificamente, temos condições de produção estritas que nos permitem identificar melhor esse discurso. A Constituição de 1988 havia outorgado ao Estado o papel de prover as políticas sociais enquanto políticas universais, mas segundo Montaño (2008, p.33) "os custos dessa função pública estatal tornaram-se muito altos para a necessidade de acumulação", de modo que ele passa a diminuir essa função. O modelo de afastamento do Estado de sua função pública universalista é efetivado a partir da aplicação dos preceitos neoliberais, que implicam uma mudança, de uma "lógica de Estado" para uma "lógica de mercado e da sociedade civil", operando, no âmbito público, uma ordem privada.

Esse movimento tem como reação uma resposta da sociedade organizada no sentido da cobrança das políticas sociais, bem como uma ação mais incisiva do Estado em prol do interesse geral, baseados na noção de oposição dos interesses de produção x socialização, que desemboca na dualidade público x privado enquanto contradição evidente. Para que o Brasil se alinhasse então a um projeto desenvolvimentista, a partir da ordem do capital e aos caminhos indicados pela crise, tal oposição deveria ser apresentada como sendo apenas aparente, pois há - e o governo estaria discursivamente tentando prová-lo - uma possibilidade de promover ações que beneficiem a todos.

\section{Algumas considerações finais}

O discurso que não revela, que não expõe as contradições, mas sim busca neutralizá-las, está intrinsecamente ligado a uma prática política de controle, de direcionamento, e não de superação. É uma neutralização que implica estabelecer novas relações entre o público e o privado, colocando novamente o Estado como esfera pública por excelência, em oposição ao mercado, entendido apenas como esfera privada, já que ele participa do público. Em suma, a oposição pretendida pelo discurso governamental é construída discursivamente apenas de forma estratégica, visto que, segundo." (MONTAÑO, 2008, p. 46) "as dimensões do púbico (sic) e do privado na sociedade capitalista, sendo esferas antiéticas, no entanto não conformam esferas isoladas, autônomas. Não é possível pensar uma sem a outra, ocupando ambas, contraditoriamente, os mesmos espaços.”.

\section{Referências}

ACHARD, Pierre. Memória e produção discursiva do sentido. In: ACHARD, P. et alli. Papel da Memória. 2 ed. São Paulo: Pontes Editores, 2007.

\footnotetext{
10 De acordo com Montaño (2008), essas contradições seriam: a) a socialização da produção e apropriação privada do seu produto; b) a liberdade (negativa) e a igualdade e a justiça social c) o papel do Estado enquanto mantenedor do status quo, ou seja, da acumulação capitalista e do interesse privado e como instrumento de desenvolvimento de maneiras que reduzam a desigualdade social e d) a realidade setorizada em: Estado, mercado e sociedade civil.
} 
ANDES (Associação Nacional dos Docentes de Ensino Superior). PDE - O Plano de Desestruturação da Educação Superior. Brasília, 2007.

BAKHTIN, Mikhail. Marxismo e filosofia da linguagem. 11.ed. São Paulo: Hucitec, 2004. BRASIL, Ministério da Educação. O Plano de Desenvolvimento da Educação: razões, princípios e programas. MEC. Disponível em: < http://portal.mec.gov.br/arquivos/livro/ index.htm>. Acesso em 17 de maio de 2009.

CAVALCANTE, Maria do Socorro A. de Oliveira. Qualidade e cidadania nas reformas da educação brasileira: o simulacro de um discurso modernizador. Maceió: LUKÁCS, Georg. O Problema da Ideologia. Tradução de Ester Vaisman. Mimeo. S.d. MARX, K. e ENGELS, F. Textos sobre educação e ensino. São Paulo: Editora Moraes, 1992. MONTAÑO, Carlos. Novas configurações do público e do privado no contexto capitalista atual: o papel ideológico do "terceiro setor". In: CURY, Carlos Roberto Jamil et all. Público e privado na educação novos elementos para o debate. São Paulo: Xamã, 2008. NEVES, Lúcia Maria Wanderley (org.). Reforma Universitária do Governo Lula. Reflexões para o debate. São Paulo: Xamã, 2004.

NETTO, José Paulo. Relendo a Teoria Marxista da História. In: SAVIANI, Demerval et alli (org). História e História da Educação. Campinas-SP: Autores Associados: HISTEDBR, 1998.

ORLANDI, Eni P. As formas do silêncio no movimento dos sentidos. São Paulo, UNICAMP, 1995 . Maio de 68: os silêncios da memória. In: ACHARD, P. et alli. Papel da Memória. 2 ed. São Paulo: Pontes Editores, 2007.

PECHÊUX, Michel. O Discurso - estrutura ou acontecimento. Campinas-SP: Pontes, 2006.

. Semântica e Discurso. Uma crítica à afirmação do óbvio.. Campinas: Editora da Unicamp, 1988. Tradução de Eni Orlandi et al. 